\title{
Research advances in the relationship between nonalcoholic fatty liver disease and atherosclerosis
}

Xin X $u^{1,2}$, Linlin Lu ${ }^{2,3}$, Quanyong Dong ${ }^{1,2}$, Xiaolin $\mathrm{Li}^{1,2}$, Nannan Zhang ${ }^{1,2}$, Yongning Xin ${ }^{1,2,3^{*}}$ and Shiying Xuan ${ }^{1,2,3^{*}}$

\begin{abstract}
Nonalcoholic fatty liver disease (NAFLD) is a metabolic stress-induced liver disease that is closely related not only to genetic susceptibility but also to insulin resistance and highly linked with metabolic syndrome. In recent years, the prevalence of NAFLD has increased rapidly, paralleling the epidemic of type 2 diabetes mellitus and obesity leading to cardiovascular disease. It has been demonstrated that NAFLD is highly associated with atherosclerosis. With recently gained knowledge, it appears that NAFLD may induce insulin resistance, dyslipidemia, oxidative stress, inflammation, and fluctuation of adipokines associated with atherosclerosis. In this review, we aimed to summarize recent discoveries related to both NAFLD and atherosclerosis, and to identify possible mechanisms linking them.
\end{abstract}

Keywords: Nonalcoholic fatty liver disease, Atherosclerosis, Insulin resistance, Metabolic syndrome, Cardiovascular disease

\section{Introduction}

Nonalcoholic fatty liver disease (NAFLD) is a chronic liver disease that occurs in patients who consume little or no alcohol [1]. It has become one of the most common liver diseases worldwide and is characterized by parenchymal cell steatosis and steatohepatitis [2, 3], which can progress to cirrhosis, with or without liver failure and hepatocellular carcinoma (HCC) in a subset of patients $[1,4]$. With increasingly sedentary lifestyle habits, NAFLD now has become the most common etiology of chronic liver disease in the US [5]. In Asian counties, the prevalence rates of $12 \%-24 \%$ [6] and in large cities in China with reported approximately $15 \%$ [7]. NAFLD can occur at any age [8,9]. NAFLD is closely associated with metabolic syndrome (MS), with nearly $90 \%$ of NAFLD patients having more than one of the following conditions: obesity, type 2 diabetes mellitus (T2DM), hypertension, and dyslipidemia [10]. Because approximately $33 \%$ of patients with NAFLD also have MS, NAFLD was widely considered to be the hepatic

\footnotetext{
*Correspondence: xinyongning@163.com; xuansydxy@163.com

'Department of Gastroenterology, Qingdao Municipal Hospital, Dalian Medical University, Qingdao, China

Full list of author information is available at the end of the article
}

manifestation of MS [11, 12], but now more like a precursor of MS [13]. Although the pathogenic mechanism of NAFLD remains uncertain, the "two-hit" theory is widely accepted by us [14]. At present, Tilg, etc. have proposed the multiple parallel hits hypothesis. They suggested that inflammatory mediators derived from various tissues but especially from the gut and adipose tissue could play a central role in the cascade of inflammation, fibrosis, and finally tumor development [15].

Atherosclerosis (AS), a pathological plaque formation within blood vessels that initiates intimal thickening (the earliest lesion in the arterial wall [16]), hardening of the arteries, and narrowing of the lumen, is a leading causative factor for cardiovascular disease (CVD). Multiple phenotypes of AS disease based on pathological features and propensity for thrombosis have recently been proposed [17] according to the modified classification of American Heart Association (AHA) [18]. The classification includes intimal xanthoma, pathological intimal thickening, fibroadenoma, thin fibrous cap atheroma, and fibrocalcific plaque. The development of atheromatous plaques with a necrotic core represents an invasion of lipid deposits by macrophages. Release of activated proteolytic enzymes damages the surrounding tissues, leading to the formation of vulnerable plaque. The
() Biomed Central

(c) 2015 Xu et al. Open Access This article is distributed under the terms of the Creative Commons Attribution 4.0 International License (http://creativecommons.org/licenses/by/4.0/), which permits unrestricted use, distribution, and reproduction in any medium, provided you give appropriate credit to the original author(s) and the source, provide a link to the Creative Commons license, and indicate if changes were made. The Creative Commons Public Domain Dedication waiver (http://creativecommons.org/publicdomain/zero/1.0/) applies to the data made available in this article, unless otherwise stated. 
pathophysiology of AS is best described by "endothelial damage theory", which implies that the components of AS, such as hypertension, dyslipidemia, etc., induce vascular intima injury to further stimulate the formation of atherosclerotic lesions. In addition, AS can become a systematic chronic inflammation involving many inflammatory cells and amboceptors [19].

\section{The association between NAFLD and AS}

NAFLD is closely linked with MS [11-13], and is highly associated with abdominal obesity, atherogenic dyslipidemia, and diabetes. exposing subjects with NAFLD to an increased risk of CVD [20]. Studies have also shown that NAFLD is linked to CVD independent of other metabolic risk factors [21] as summarized in Table 1, suggesting that it is an active contributor to the pathogenesis of atherosclerosis and is not just a marker for CVD [22]. Various pathogenic mechanisms have been suggested as possible explanations for accelerated atherosclerosis and increased CVD burden in NAFLD patients, including a high oxidative stress state due to steatosis-stimulated fatty-acid oxidation in the liver [23], systemic release of proatherogenic molecules like tumor necrosis factor- $\alpha$, interleukin- 6 , and oxidized LDL cholesterol [24], increased IR [25], and macrophage activation [26]. The atherogenic role of hepatic inflammation is also supported by the fact that patients with NASH have increased atherosclerosis when compared with patients with simple steatosis $[27,28]$. Carotid intima-media thickness (CIMT) is a reliable index of subclinical atherosclerosis [29] and a mirror of atherosclerosis progression in NAFLD patients. Observational studies suggest that NAFLD is associated with increased CIMT and carotid plaques in both children and adults [30]. Therefore, NAFLD is closely associated with AS and it seems to an early risk factor for AS.

Generally, the increased risk of CVD in NAFLD patients [31,32] might reflect the coexistence of MS components. This may suggest that NAFLD confers a cardiovascular risk above or even beyond its association with the individual components of MS [33]. The high prevalence of NAFLD in AS patients has stimulated an interest in the possible role of the liver in the development of AS. Therefore, identification of the mechanism linking NAFLD and AS may be helpful in the development of a therapeutic target in AS [34] and in the prevention and treatment of CVD in early NAFLD patients.

\section{Possible mechanisms linking NAFLD and AS}

NAFLD can contribute to and aggravate AS development, but the precise mechanism remains unclear. The following display possible linkages between these conditions at the molecular level.
Table 1 Clinical studies about the link between NAFLD and AS

\begin{tabular}{ll}
\hline Author, year & $\begin{array}{l}\text { NAFLD/NASH is associated with } \\
\text { AS-related phenotypes }\end{array}$ \\
\hline Mishra S, 2013 [115] & $\begin{array}{l}\text { NAFLD is associated with carotid intima-media } \\
\text { thickness }\end{array}$ \\
Li N, 2014 [116] & $\begin{array}{l}\text { NAFLD is associated with carotid artery wall } \\
\text { thickness }\end{array}$ \\
Colak Y, 2012 [117] &
\end{tabular}

Sunbul M, 2014 [118]

Kozakova M, 2012 [119] NAFLD as estimated by the fatty liver index is associated with early carotid plaques in middle-aged nondiabetic subjects

Yilmaz Y, 2010 [120] NAFLD is associated with decreased coronary flow reserve

Pacifico L, 2010 [121] NAFLD is associated with reduced brachial artery flow-mediated vasodilation and increased carotid artery wall thickness

Alkhouri N, 2011 [122] NAFLD is associated with increased arterial stiffness and reduced brachial artery flow-mediated vasodilation

Villanova N,2005 [123] NAFLD histology is associated with reduced

Colak Y, 2012 [117] brachial artery flow-mediated vasodilation

Ampuero J, 2015 [124] NAFLD is associated with carotid intima-media thickness and carotid plaques (meta-analysis of 14 studies involving 4130 subjects)

Guleria A, 2013 [125]

NAFLD is associated with carotid intima-media

Torun E, 2013 [126] thickness and flow-mediated dilatation \%

Chen $Y, 2015$ [127]

NAFLD is associated with carotid intima-media thickness and brachial-ankle pulse wave velocity in patients with advanced fibrosis

Ozturk K, 2015 [128]

NAFLD is associated with PWW, CIMT and FMD levels in young adult men

Pastori D, 2015 [129]

NAFLD is associated with FMD level in patients with cardiometabolic risk factors.

Puiq J, 2015 [130]

NAFLD is associated with CIMT in morbid obesity

Kim SK, 2014 [131] Nonalcoholic Fatty liver disease is associated with increased carotid intima-media thickness only in type 2 diabetic subjects with insulin resistance

Kucukazman M, 2013 [11] NAFLD is associated with CIMT and FMD levels

\section{Insulin resistance (IR)}

IR, as the "first-hit" to the liver, contributes to the development of both NAFLD and AS by disrupting cellular energy metabolism, damaging the peripheral tissue, interfering with the ingestion and synthesis of liver fatty acid, and promoting fatty acid accumulation in the benign liver, which leads to hepatic IR due to a lack of suppression of endogenous liver glucose production [35]. NAFLD patients with IR experienced additional stresses to the liver based on the presence of hyperglycemia, hyperinsulinemia, hyperlipidemia, and damage to 
the vascular endothelial cells (VECs). All of these factors participate in the development of AS. Furthermore, increased VEC adherence can induce proliferation of smooth muscle cells (SMCs) and promote the synthesis and release of growth and inflammation factors in various pathways, which contributes to the progression of AS.

\section{Dyslipidemia}

Given that the regulation of lipid influx, synthesis, and metabolism is disturbed in the liver of NAFLD patients, NAFLD is associated with dyslipidemia, which leads to an up-regulation of the sterol regulatory element binding protein-1c (SREBP-1c), a transcription factor for some de-novo lipogenesis genes, to inhibition of the free fatty acid (FFA) oxidation and stimulation of liver fat content (LFC) [35-37]. Likewise, SREBP-2 and low-density lipoprotein (LDL) receptor are down-regulated in NAFLD patients, leading to inhibition of cholesterol uptake and very low-density lipoprotein (VLDL) synthesis in liver cells, resulting in an increase in hepatic triglycerides (TG) [36]. Increased TG levels can further disturb the atherogenic lipid profile by lowing high-density lipoprotein cholesterol (HDL-C) (an anti-AS factor) [37] and increasing small and dense LDL particles and oxidated LDL (ox-LDL) [38]. Ox-LDL contributes directly to AS and accelerates the development of local atherosclerotic plaques [39] as a key molecular connection between NAFLD and AS. Furthermore, as blood FFAs are increased due to increased energy intake and decreased FFA oxidation [40], endothelial cells (ECs) can be affected morphologically with shrinkage and intercellular space dilatation. With an increase in cellular permeability, serum remnant-like particle cholesterol (RLP-C) can easily gain access into ECs and block and interfere cellular activity, leading to AS [41]. Additionally, FFAs could disturb the insulin level by inhibition of its gene transcription through Jun N-terminal kinase (JNK) [42] to contribute to IR and promote the development of AS.

\section{Oxidative stress and lipid peroxidation (LPO)}

Oxidative stress and lipid peroxidation (LPO), as the "second-hit" to the liver in the development of NAFLD, may be another important mechanism linking NAFLD with AS. Oxidative stress is an imbalanced situation in which the body's production of reactive oxygen species (ROS) exceeds its capability for ROS detoxification, causing tissue damage [43]. ROS can be produced by increased activity of reduced nicotinamide adenine nucleoside phosphate (NADPH) oxidase through activation of phosphate kinase $C$ (PKC) or by increase of $\beta$-oxidation of peroxisomes and $\omega$-oxidation of microsomes. It induces levels of inflammatory factors [44], depletes NO [45], destroys the endothelium-dependent vasodilatation function [46], reduces the elasticity of blood vessels, promotes endothelial cell apoptosis [47], contributes to vessel smooth muscle cell hyperplasia [48, 49], causes endoplasmic reticulum (ER) stress, leads to hyperlipidemia, promotes apoptosis of macrophages in the atherosclerotic plaque, and induces ox-LDL through LPO [50, 51]. All of these metabolic derangement clearly indicate that NAFLD is potential strongly associated with AS.

\section{Inflammation}

Inflammation can induce IR [52], whereas reduction of inflammation prevents IR development [53]. In NAFLD patients, inflammation appears as an increases in the levels of cytokines interleukin (IL)-6 and tumor necrosis factor (TNF)- $\alpha, \mathrm{C}$-reactive protein (CRP), and monocyte chemoattractant protein-1 (MCP-1) in peripheral blood [54]. Increased hepatic expression of IL-6 and increased blood levels of IL-6 may promote partial liver injury and AS [51]. IL-6 can activate macrophages to secrete matrix metalloproteinase-1 (MMP-1), induce mononuclear cells (MNCs) to participate in the development of vessel plaque, promote synthesis of LDL receptor and influx of LDL into macrophages, enhance lipid deposition, and stimulate vascular smooth muscle cell (VSMC) proliferation [55]. Inflammation and IR, therefore, participate in the development of AS [56].

\section{Matrix metalloproteinase (MMP)}

MMPs, a main enzyme family involved in degradation of extracellular matrix, is secreted predominantly by MNCs, macrophages, and VSMCs. An increase in MMP expression is detected in NAFLD patients [57], and this increase may play a role in the course of liver fibrosis and in the process or fracture of AS by degradation of fibrous cap disruption of plaque and promotion of thrombus formation preceded by formation of a vulnerable atherosclerotic plaque.

\section{Levels of Adipokines}

Adiponectin (APN), which is secreted by adipocytes, can enhance insulin sensitivity in the liver and other tissues to reduce the level of serum fatty acids and increase the oxidation of fatty acids in the muscle [58]. It has been found that APN levels are low in NAFLD patients independent of metabolic disorder [54]. Althouth an increase in APN expression can reduce TG, total cholesterol, and LDL-C concentrations [59], stimulate vascular endothelial nitric oxide synthase (eNOS) mRNA expression, and progressively reduce atherosclerotic lesions. The possible mechanism may involve increases in superoxide dismutase (SOD) and eNOS activities as well as APN expression, a decrease in MDA levels [60], and inhibition of macrophage scavenger receptor A1 expression and transformation to foam cells, inhibition 
of VSMC proliferation and migration to suppress plaque disruption, and an increase in competitive binding between platelet growth factor (PDGF) and the BB receptor to suppress signal transduction. It has been demonstrated that APN inhibits the EC inflammatory reaction by affecting the nuclear factor (NF)- $\mathrm{KB}$ signaling pathway [60, 61], another key molecular pathway involved in AS.

Leptin, which is predominately produced by adipose tissue, plays an important role in regulating food intake and energy expenditure and has been found to be elevated in NAFLD patients [60] in association with disease severity [62]. In addition, leptin plays a crucial role in aggravation of NASH [63, 64] and attenuation of AS. Endogenous leptin resistance is associated with IR with a synergistic effect. It can surpress apolipoprotein $M$ and APN levels, reduce NO synthesis by activating the PI3-Akt-eNOS pathway [65], stimulate IMT, and serve as a predictor of CVD [66].

Visfatin, a new adipocytokine expressed in visceral adipose tissue (VAT) and with nicotinamide phosphoribosyltransferase (NAMPT) activity, is associated with some of AS risk factors such as inflammation, endothelial dysfunction, vascular endothelial proliferation, and atherosclerotic plaque formation. Visfatin has been suggested as a new indicator of the severity of NAFLD, as its expression is closely and positively associated with the degree of liver steatosis [67] and increased in the foamy macrophages of AS plaques. Overexpression of visfatin induces foamy macrophages to secrete MMP [68]. Therefore, visfatin may be involved in the processes of both AS and NAFLD.

Chemerin, a chemoattractant protein, is highly expressed in the white adipose tissue (WAT) and liver of NAFLD patients and functions to attract macrophages and immature dendritic cells (DCs) via binding with a chemotaxis receptor. It has been suggested that chemerin may be closely related to risk factors of CVD (such as hypertension) [69] and play a critical role in the development of both NAFLD and AS, although the precise mechanism still needs to be investigated.

Omentin, a cytokine expressed in omental adipose tissues, has an anti-inflammatory effect and can increase insulin sensitivity. It also has a vascular relaxation effect via the regulation of NOS expression [70]. A significant reduction in omentin expression in NAFLD patients may imply a connection between omentin and AS.

Retinol-binding protein 4 (RBP4), a specific retinal transfer protein, is compounded and secreted by liver cells for binding and transportation of retinal from blood into cells. RBP4 expression is increased upon liver injury, NASH (as a sensitive maker of NASH) [71], or coronary heart disease (especially with acute coronary syndrome [ACS] [72] and thus, has been proposed to be a new risk factor for coronary heart disease [73]. Accumulating evidence suggests that RBP4 can inhibit insulin activity in ECs, weaken the level of NO, and promote endothelial dysfunction [74] in the development of AS. Furthermore, gene expression of RBP4 has become a sign of inflammation [25-76] in association with AS. However, the detailed molecular interaction that occurs in the progression of NAFLD and AS remains to be elucidated.

Resistin is closely associated with NAFLD and AS [77] via the following possible mechanisms: (1) resistin causes vascular endothelial dysfunction by increasing the release and expression of vascular cell adhesion molecule-1 (VCAM-1), intercellular adhesion molecule (ICAM)-1, and pentraxin-3 (PTX-3); by decreasing tumor necrosis factor receptor-associated factor (TR-AF)-3 expression to induce CD40 and MCP-1 expression; by inducing P selectin expression to stimulate NADPH oxidase activity; and by enhancing the adhesion of monocytes as well as NF- $\mathrm{KB}$ and activator protein-1 activities [78]. (2) NF- $\mathrm{kB}$ and peroxisome proliferator activated receptor-y (PPARy) can regulate resistin secretion, and the NF- $\mathrm{kB}$ signaling pathway plays an important role in the progression of AS with the participation of resistin [79]. (3) Resistin promotes SMC proliferation by activating the corresponding signaling transduction pathway [80, 81], enhances the migratory ability of SMCs [82], and induces oxidative stress and an inflammatory reaction under dyslipidemia. Therefore, resistin is involved in NAFLD and acts as an indicator of the severity of AS [83].

\section{Intestinal microbiota}

A great deal of data have shown that the intestinal microbiota was a risk factor of contributing to the development of NAFLD [84]. The mechanism underlying may as follows: the level of lipopolysaccharide (LPS) derived by intestinal microbiota was increased in NAFLD patients, and when increased plasma endotoxin concentration in the portal vein, the clearance ability of the hepatic Kupffer cells may become overloaded [85], leading to systemic endotoxaemia and mild chronic inflammation [86], inducing chronic liver disease [87]. Indeed, numerous studies support a complicated relationship between the intestinal microbiota and obesity. Obese individuals are thought to have increased the intestinal permeability [88], potentially inducing an increased endotoxin load in the portal vein and ensuing overload of the hepatic Kupffer cells. Obesity and NAFLD are important risk factors for the development of AS and subsequent CVD. In fact, intestinal microorganisms also seem to be involved in AS. Study showing that plasma endotoxin levels above 90 percent were linked with a three-time increase in cardiovascular event risk [89], and animal experiments clearly indicating that endotoxin injection accelerates cholesterol-induced AS [90]. Besides, numerous studies have showing intestinal 
microbiota was closely link with IR, which is the common mechanism of NAFLD and AS.

\section{Fetuin- $A$}

Fetuin-A, a a-2-HS-Glycoprotein, is a multifunctionprotein synthesized in the liver and secreted into the circulation [91]. It is not only an endogenous inhibitor of insulin receptor tyrosine kinase in the skeletal muscle, but in the liver [92] resulting in IR. Furthermore, Pal et al. currently showed that Fetuin-A acts as an endogenous ligand for toll-like receptor 4 (TLR4) and enhances both IR and inflammation [93]. High level of Fetuin-A is closely associated with IR, atherogenic dyslipidemia, elevated inflammatory cytokines, and decreased adiponectin levels [94]. These findings suggest that Fetuin-A may contribute to both the course of NAFLD and development of AS, and it is increased in NAFLD subjects. However, this glycoprotein inhibits ectopic calcification, a reduction level of Fetuin-A might promote cardiovascular calcifications [94]. Moreover, this glycoprotein is an inhibitor of transforming growth factor-b1 (TGF-b1), a major pro-fibrogenic growth factor promoteing fibrotic changes in the liver and arteries [95]. As mentioned above, we may reasonable speculate that higher level of fetuin-A could prevent NAFLD and AS development. Despite the function of Fetuin-A for NAFLD and AS remains controversial, but it may be a link between NAFLD and AS.

\section{Obstructive sleep apnea (OSA)}

OSA is one of the most common types of sleep apnea [96] and is closely related to NAFLD (sharing it with similar risk factors) [97] and early-stage AS, as determined by the CIMT and pulse-wave velocity (PWV) [98, 99]. Increased CIMT was found in OSA patients [100], and OSA is pathologically related to CVD and AS [101]. The possible mechanistic links between AS and OSA may be intermittent hypoxia and oxidative stress, the inflammatory cascade, endothelial dysfunction, mechanical and hemodynamic factors, and platelet activation and coagulation abnormalities [102].

\section{Heart-type fatty acid binding protein (H-FABP)}

$\mathrm{H}$-FABP, a cytosolic protein, transports fatty acids in cardiomyocytes. It regulates the mitochondrial betaoxidative system within cardiomyocytes and accounts for $10 \%$ of cytosolic protein in these cells [103]. Serum $\mathrm{H}$-FABP is highly sensitive to myocardial ischemia and used as a diagnostic biochemical indicator of ACS [104]. $\mathrm{H}$-FABP is closely related to NAFLD and AS. H-FABP levels are elevated in NAFLD patients and significantly and positively linked to the CIMT (the early marker of subclinical AS) [105].

\section{Chronic kidney disease (CKD)}

It has been discovered that NAFLD is positively associated with CKD [106-108]; however, the possible mechanism remains vague. Both NAFLD and CKD can increase the risk of CVD [109, 110]. Obviously, a CKD-specific bone mineral disturbance can strongly induce the calcification of plaques and substantially promote AS development. Therefore, NAFLD may affect or accelerate the development of CVD with CKD [111].

\section{Others}

Markers of fibrinolytic and hemostatic function (such as plasminogen activator inhibitor-1 antigen) are closely linked with NAFLD, AS, and CVD [112, 113].

\section{Conclusion}

NAFLD is a metabolic stress-induced liver disease that is closely related to IR and highly linked with MS. In recent years, the prevalence of NAFLD has increased rapidly with a higher concurrence in the patients with T2DM and AS leading to CVD. NAFLD has emerged as a public health problem worldwide and is highly associated AS, It has been demonstrated that NAFLD leads to an increased risk of cardiovascular events and mortality [114]. The mechanism linking NAFLD and AS is poorly understood and may be related to IR, inflammation, oxidative stress, lipid disorders, MMP activity, fatty hormone levels, CKD, and OSA. We discussed and summarized the available evidence in an attempt to reveal the mechanistic connection between these two common pathological conditions.

\section{Competing interests}

The authors declared that they have no competing interests.

\section{Authors' contributions}

XS designed research. XX and LL performed literature search and wrote the paper. XY critically revised the paper. DQ, LX and ZN checked the paper.

\section{Acknowledgements}

The authors would like to thank the participants for their commitment and contribution to the study. This study was in part supported by a grant from our hospital.

\section{Author details}

'Department of Gastroenterology, Qingdao Municipal Hospital, Dalian Medical University, Qingdao, China. ${ }^{2}$ Digestive Disease Key Laboratory of Qingdao, Qingdao, China. ${ }^{3}$ Central Laboratories, Qingdao Municipal Hospital, Qingdao, China.

Received: 20 May 2015 Accepted: 22 October 2015

Published online: 03 December 2015

\section{References}

1. Neuschwander-Tetri BA, Caldwell SH. Nonalcoholic steatohepatitis: summary of an AASLD single topic conference. Hepatology. 2003;37(5):1202-19.

2. Angulo P, Lindor KD. Non-alcoholic fatty liver disease. J Gastroenterol Hepatol. 2002;17(Suppl):S186-90.

3. Angulo P. Obesity and nonalcoholic fatty liver disease. Nutr Rev. 2007;65(6 Pt 2):S57-63. 
4. Dowman JK, Tomlinson JW, Newsome PN. Pathogenesis of non-alcoholic fatty liver disease. QJM. 2010;103(2):71-83.

5. Souza MR, Diniz Mde F, Medeiros-Filho JE, Araújo MS. Metabolic syndrome and risk factors for non-alcoholic fatty liver disease. Arq Gastroenterol. 2012;49(1):89-96

6. Farrell GC, Chitturi S, Lau GK, Sollano JD. Asia-Pacific Working Party on NAFLD. Guidelines for the assessment and management of non-alcoholic fatty liver disease in the Asia-Pacific region: executive summary. J Gastroenterol Hepatol. 2007;22(6):775-7.

7. Fan JG, Farrell GC. Epidemiology of non-alcoholic fatty liver disease in China. J Hepatol. 2009;50(1):204-10.

8. Li X, Xia M, Ma H, Hofman A, Hu Y, Yan H, et al. Liver fat content is associated with increased carotid atherosclerosis in a Chinese middleaged and elderly population: the Shanghai Changfeng study. Atherosclerosis. 2012;224(2):480-5

9. Akin L, Kurtoglu S, Yikilmaz A, Kendirci M, Elmalı F, Mazicioglu M, et al. Fatty liver is a good indicator of subclinical atherosclerosis risk in obese children and adolescents regardless of liver enzyme elevation. Acta Paediatr. 2013;102(3):e107-13.

10. Chalasani N, Younossi Z, Lavine JE, Diehl AM, Brunt EM, Cusi K, et al. The diagnosis and management of non-alcoholic fatty liver disease: practice guideline by the american gastroenterological association, american association for the study of liver diseases, and american college of gastroenterology. Gastroenterology. 2012;142(7):1592-609.

11. Kucukazman M, Ata N, Yavuz B, Dal K, Sen O, Deveci OS, et al. Evaluation of early atherosclerosis markers in patients with nonalcoholic fatty liver disease. Eur J Gastroenterol Hepatol. 2013;25(2):147-51.

12. Kotronen A, Yki-Jarvinen H. Fatty liver: a novel component of the metabolic syndrome. Arterioscler Thromb Vasc Biol. 2008;28(1):27-38.

13. Lonardo A, Ballestri S, Marchesini G, Angulo P, Loria P. Nonalcoholic fatty liver disease: a precursor of the metabolic syndrome. Dig Liver Dis. 2015;47(3):181-90.

14. Jou J, Choi SS, Diehl AM. Mechanisms of disease progression in nonalcoholic fatty liver disease. Semin Liver Dis. 2008;28(4):370-9.

15. Tilg $H$, Moschen AR. Evolution of inflammation in nonalcoholic fatty liver disease: the multiple parallel hits hypothesis. Hepatology. 2010;52(5):1836-46.

16. Gaudio E, Carpino G, Grassi M, Musca A. Morphological aspects of atherosclerosis lesion: past and present. Clin Ter. 2006;157(2):135-42.

17. Virmani R, Kolodgie FD, Burke AP, Farb A, Schwartz SM. Lessons from sudden coronary death: a comprehensive morphological classification scheme for atherosclerotic lesions. Arterioscler Thromb Vasc Biol. 2000;20(5):1262-75.

18. Bhanvadia VM, Desai NJ, Agarwal NM. Study of coronary atherosclerosis by modified american heart association classification of atherosclerosis-an autopsy study. J Clin Diagn Res. 2013;7(11):2494-7.

19. Hansson GK. Inflammation, atherosclerosis, and coronary artery disease. N Engl J Med. 2005;352(16):1685-95.

20. Silaghi CA, Silaghi H, Crăciun AE, Fărcaș A, Colosi HA, Cosma DT, et al. Age, abdominal obesity, and glycated hemoglobin are associated with carotid atherosclerosis in type 2 diabetes patients with nonalcoholic fatty liver disease. Med Ultrason. 2015;17(3):300-7.

21. Targher G, Arcaro G. Non-alcoholic fatty liver disease and increased risk of cardiovascular disease. Atherosclerosis. 2007;191:235-40.

22. Targher G, Bertolini L, Padovani R, Rodella S, Tessari R, Zenari L, et al. Prevalence of nonalcoholic fatty liver disease andits association with cardiovascular disease among type 2 diabetic patients. Diabetes Care. 2007;30:1212-8

23. Targher G, Day CP, Bonora E. Risk of cardiovascular disease in patients with nonalcoholic fatty liver disease. N Engl J Med. 2010;363:1341-50.

24. Targher G, Bertolini L, Padovani R, Rodella S, Zoppini G, Pichiri I, et al. Prevalence of non-alcoholic fatty liver disease and its association with cardiovascular disease in patients with type 1 diabetes. J Hepatol. 2010;53:713-8

25. Gaggini M, Morelli M, Buzzigoli E, DeFronzo RA, Bugianesi E, Gastaldelli A, et al. Non-alcoholic fatty liver disease (NAFLD) and its connection with insulin resistance, dyslipidemia, atherosclerosis and coronary heart disease. Nutrients. 2013;5:1544-60.

26. Bieghs V, Rensen PC, Hofker MH, Shiri-Sverdlov R. NASH and atherosclerosis are two aspects of a shared disease: central role for macrophages. Atherosclerosis. 2012;220:287-93.
27. Adams LA, Lymp JF, St Sauver J, Sanderson SO, Lindor KD, Feldstein A, et al. The natural history of nonalcoholic fatty liver disease: a population-based cohort study. Gastroenterology. 2005;129:113-21.

28. Ekstedt M, Franzén LE, Mathiesen UL, Thorelius L, Holmqvist M, Bodemar G, et al. Long-term follow-up of patients with NAFLD and elevated liver enzymes. Hepatology. 2006;44:865-73.

29. O'Leary DH, Polak JF. Intima-media thickness: a tool for atherosclerosis imaging and event prediction. Am J Cardiol. 2002;90:18L-21L.

30. Madan SA, John F, Pyrsopoulos N, Pitchumoni CS. Nonalcoholic fatty liver disease and carotid artery atherosclerosis in children and adults: a metaanalysis. Eur J Gastroentreol Hepatol. 2015;27(11):1237-48.

31. Loria P, Lonardo A, Bellentani S, Day CP, Marchesini G, Carulli N, et al. Nonalcoholic fatty liver disease (NAFLD) and cardiovascular disease: an open question. Nutr Metab Cardiovasc Dis. 2007;17(9):684-98.

32. Anstee QM, Targher G, Day CP. Progression of NAFLD to diabetes mellitus, cardiovascular disease or cirrhosis. Nat Rev Gastroenterol Hepatol. 2013;10(6):330-44.

33. Hamaguchi M, Kojima T, Takeda N, Nagata C, Takeda J, Sarui H, et al. Nonalcoholic fatty liver disease is a novel predictor of cardiovascular disease. World J Gastroenterol. 2007;13(10):1579-84.

34. Gupte AA, Lyon CJ, Hsueh WA. Nuclear factor (erythroid-derived 2)-like-2 factor (Nrf2), a key regulator of the antioxidant response to protect against atherosclerosis and nonalcoholic steatohepatitis. Curr Diab Rep. 2013;13(3):362-71.

35. Severova MM, Saginova EA, Galliamov MG, Ermakov NV, Rodina AV, Fomin $W$, et al. Clinicopathogenetic characteristics of cardiorenal syndrome in non-alcoholic fatty liver disease. Ter Arkh. 2012;84(6):15-20.

36. Nakamuta M, Fujino T, Yada R, Yada M, Yasutake Y, Yoshimoto T, et al. Impact of cholesterol metabolism and the LXRalpha-SREBP-1c pathway on nonalcoholic fatty liver disease. Int J Mol Med. 2009;23(5):603-8.

37. Lee JM, Choudhury RP. Atherosclerosis regression and high-density lipoproteins. Expert Rev Cardiovasc Ther. 2010;8(9):1325-34.

38. Czyzewska M, Wolska A, Cwiklińska A, Kortas-Stempak B, Wróblewska M. Disturbances of lipoprotein metabolism in metabolic syndrome. Postepy Hig Med Dosw (Online). 2010;64:1-10.

39. Gouni-Berthold I, Sachinidis A. Possible non-classic intracellular and molecular mechanisms of LDL cholesterol action contributing to the development and progression of atherosclerosis. Curr Vasc Pharmacol. 2004;2(4):363-70.

40. Fabbrini E, Sullivan S, Klein S. Obesity and nonalcoholic fatty liver disease: biochemical, metabolic, and clinical implications. Hepatology. 2010;51(2):679-89.

41. Boden G. Obesity and free fatty acids. Endocrinol Metab Clin North Am. 2008;37(3):635-46.

42. Solinas G, Naugler W, Galimi F, Lee MS, Karin M, et al. Saturated fatty acids inhibit induction of insulin gene transcription by JNK-mediated phosphorylation of insulin-receptor substrates. Proc Natl Acad Sci U S A. 2006;103(44):16454-9.

43. Delbosc S, Paizanis E, Magous R, Araiz C, Dimo T, Cristol JP, et al. Involvement of oxidative stress and NADPH oxidase activation in the development of cardiovascular complications in a model of insulin resistance, the fructose-fed rat. Atherosclerosis. 2005;179(1):43-9.

44. Carreau A, Kieda C, Grillon C. Nitric oxide modulates the expression of endothelial cell adhesion molecules involved in angiogenesis and leukocyte recruitment. Exp Cell Res. 2011;317(1):29-41.

45. Potdar S, Kavdia M. NO/peroxynitrite dynamics of high glucose-exposed HUVECs: chemiluminescent measurement and computational model. Microvasc Res. 2009;78(2):1-8. 19

46. Xi H, Akishita M, Nagai $K, Y u$ W, Hasegawa $H$, Eto $M$, et al. Potent free radical scavenger, edaravone, suppresses oxidative stress-induced endothelial damage and early atherosclerosis. Atherosclerosis. 2007;191(2):281-9.

47. Xu ZR, Hu L, Cheng LF, Qian Y, Yang YM. Dihydrotestosterone protects human vascular endothelial cells from $\mathrm{H}(2) \mathrm{O}(2)$-induced apoptosis through inhibition of caspase-3, caspase-9 and p38 MAPK. Eur J Pharmacol. 2010;643(2-3):254-9.

48. Migdal C, Serres M. Reactive oxygen species and oxidative stress. Med Sci (Paris). 2011;27(4):405-12

49. Cohen RA, Tong X. Vascular oxidative stress: the common link in hypertensive and diabetic vascular disease. J Cardiovasc Pharmacol. 2010;55(4):308-16.

50. Basseri S, Austin RC. Endoplasmic reticulum stress and lipid metabolism: mechanisms and therapeutic potential. Biochem Res Int. 2012;2012:841362 
51. Kaneto H, Katakami N, Matsuhisa M, Matsuoka TA. Role of reactive oxygen species in the progression of type 2 diabetes and atherosclerosis. Mediators Inflamm. 2010;2010:453892.

52. Cai D, Yuan M, Frantz DF, Melendez PA, Hansen L, Lee J, et al. Local and systemic insulin resistance resulting from hepatic activation of IKK-beta and NF-kappaB. Nat Med. 2005;11(2):183-90.

53. Tang T, Zhang J, Yin J, Staszkiewicz J, Gawronska-Kozak B, Jung DY, et al. Uncoupling of inflammation and insulin resistance by NF-kappaB in transgenic mice through elevated energy expenditure. J Biol Chem. 2010;285(7):4637-44.

54. Haukeland JW, Damås JK, Konopski Z, Løberg EM, Haaland T, Goverud I, et al. Systemic inflammation in nonalcoholic fatty liver disease is characterized by elevated levels of CCL2. J Hepatol. 2006;44(6):1167-74.

55. Schuett H, Luchtefeld M, Grothusen C, Grote K, Schieffer B, et al. How much is too much? Interleukin- 6 and its signalling in atherosclerosis. Thromb Haemost. 2009;102(2):215-22

56. Guilherme A, Virbasius JV, Puri V, Czech MP. Adipocyte dysfunctions linking obesity to insulin resistance and type 2 diabetes. Nat Rev Mol Cell Biol. 2008;9(5):367-77.

57. Toyoda H, Kumada T, Kiriyama S, Tanikawa M, Hisanaga $Y$, Kanamori A, et al. Higher hepatic gene expression and serum levels of matrix metalloproteinase-2 are associated with steatohepatitis in non-alcoholic fatty liver diseases. Biomarkers. 2013;18(1):82-7.

58. Polyzos SA, Kountouras J, Zavos C, Tsiaousi E. The role of adiponectin in the pathogenesis and treatment of non-alcoholic fatty liver disease. Diabetes Obes Metab. 2010;12(5):365-83.

59. Wang X, Pu H, Ma C, Jiang T, Wei Q, Zhang C, et al. Adiponectin abates atherosclerosis by reducing oxidative stress. Med Sci Monit. 2014;20:1792-800.

60. Hansen T, Ahlström H, Söderberg S, Hulthe J, Wikström J, Lind L, et al. Visceral adipose tissue, adiponectin levels and insulin resistance are related to atherosclerosis as assessed by whole-body magnetic resonance angiography in an elderly population. Atherosclerosis. 2009;205(1):163-7.

61. Martín-Ventura JL, Blanco-Colio LM, Muñoz-García B, Gómez-Hernández A, Arribas A, Ortega L, et al. NF-kappaB activation and Fas ligand overexpression in blood and plaques of patients with carotid atherosclerosis: potential implication in plaque instability. Stroke. 2004;35(2):458-63.

62. Fitzpatrick E, Mitry RR, Quaglia A, Hussain MJ, DeBruyne R, Dhawan A. Serum levels of CK18 M30 and leptin are useful predictors of steatohepatitis and fibrosis in paediatric NAFLD. J Pediatr Gastroenterol Nutr. 2010;51(4):500-6.

63. Imajo K, Fujita K, Yoneda M, Nozaki Y, Ogawa Y, Shinohara Y, et al. Hyperresponsivity to low-dose endotoxin during progression to nonalcoholic steatohepatitis is regulated by leptin-mediated signaling. Cell Metab. 2012;16(1):44-54.

64. Kwon DH, Kang W, Nam YS, Lee MS, Lee IY, Kim HJ, et al. Dietary protein restriction induces steatohepatitis and alters leptin/signal transducers and activators of transcription 3 signaling in lactating rats. J Nutr Biochem. 2012;23(7):791-9.

65. Vecchione C, Maffei A, Colella S, Aretini A, Poulet R, Frati G, et al. Leptin effect on endothelial nitric oxide is mediated through Akt-endothelial nitric oxide synthase phosphorylation pathway. Diabetes. 2002;51(1):168-73.

66. Wolk R, Berger P, Lennon RJ, Brilakis ES, Johnson BD, Somers VK. Plasma leptin and prognosis in patients with established coronary atherosclerosis. J Am Coll Cardiol. 2004;44(9):1819-24.

67. $\mathrm{Xu} \mathrm{H}$, Deng $Y$. The expression and meaning of Visfatin in nonalcoholic fatty liver disease rat liver tissue. J Chin Physician. 2014;16(5):616-9.

68. Dahl TB, Yndestad A, Skjelland M, Øie E, Dahl A, Michelsen A, et al. Increased expression of visfatin in macrophages of human unstable carotid and coronary atherosclerosis: possible role in inflammation and plaque destabilization. Circulation. 2007;115(8):972-80.

69. Yan Q, Zhang Y, Hong J, Gu W, Dai M, Shi J, et al. The association of serum chemerin level with risk of coronary artery disease in Chinese adults. Endocrine. 2012;41(2):281-8.

70. Wang CC, Lin SK, Tseng YF, Hsu CS, Tseng TC, Lin HH, et al. Elevation of serum aminotransferase activity increases risk of carotid atherosclerosis in patients with non-alcoholic fatty liver disease. J Gastroenterol Hepatol. 2009;24(8):1411-6.

71. Alkharfy KM, Al-Daghri NM, Vanhoutte PM, Krishnaswamy S, Xu A. Serum retinol-binding protein 4 as a marker for cardiovascular disease in women. PLoS One. 2012;7(10):e48612.

72. Mao Z, Chen R, Zhao L. Effect of recombinant human growth hormone on postoperative fatigue syndrome in patients after cardiac operations. Zhonghua Yi Xue Za Zhi. 2002;82(11):762-5.
73. Graham TE, Yang Q, Blüher M, Hammarstedt A, Ciaraldi TP, Henry RR, et al. Retinol-binding protein 4 and insulin resistance in lean, obese, and diabetic subjects. N Engl J Med. 2006;354(24):2552-63.

74. Salgado-Somoza A, Teijeira-Fernández E, Rubio J, Couso E, GonzálezJuanatey JR, Eiras $S$, et al. Coronary artery disease is associated with higher epicardial retinol-binding protein 4 (RBP4) and lower glucose transporter (GLUT) 4 levels in epicardial and subcutaneous adipose tissue. Clin Endocrinol (Oxf). 2012;76(1):51-8.

75. Yamawaki H, Tsubaki N, Mukohda M, Okada M, Hara Y. Omentin, a novel adipokine, induces vasodilation in rat isolated blood vessels. Biochem Biophys Res Commun. 2010;393(4):668-72.

76. Yu M, Ishibashi-Ueda H, Ohta-Ogo K, Gabbiani G, Yamagishi M, Hayashi $K$, et al. Transient expression of cellular retinol-binding protein-1 during cardiac repair after myocardial infarction. Pathol Int. 2012;62(4):246-53.

77. Pagano C, Soardo G, Pilon C, Milocco C, Basan L, Milan G, et al. Increased serum resistin in nonalcoholic fatty liver disease is related to liver disease severity and not to insulin resistance. J Clin Endocrinol Metab. 2006;91(3):1081-6.

78. Manduteanu I, Pirvulescu M, Gan AM, Stan D, Simion V, Dragomir E, et al. Similar effects of resistin and high glucose on P-selectin and fractalkine expression and monocyte adhesion in human endothelial cells. Biochem Biophys Res Commun. 2010;391(3):1443-8.

79. Silswal N, Singh AK, Aruna B, Mukhopadhyay S, Ghosh S, Ehtesham NZ Human resistin stimulates the pro-inflammatory cytokines TNF-alpha and IL-12 in macrophages by NF-kappaB-dependent pathway. Biochem Biophys Res Commun. 2005;334(4):1092-101.

80. Pandian S, Amuthan V, Sukumar P, Janarthanan RA, Murugan S, Palanichamy $S$, et al. Plasma CRP level predicts left ventricular function and exercise capacity in patients with acute myocardial infarction. Indian Heart J. 2005;57(1):54-7.

81. Jung HS, Park KH, Cho YM, Chung SS, Cho HJ, Cho SY, et al. Resistin is secreted from macrophages in atheromas and promotes atherosclerosis. Cardiovasc Res. 2006;69(1):76-85.

82. Calabro P, Samudio I, Willerson JT, Yeh ET. Resistin promotes smooth muscle cell proliferation through activation of extracellular signal-regulated kinase 1/2 and phosphatidylinositol 3-kinase pathways. Circulation. 2004;110(21):3335-40.

83. Reilly MP, Lehrke M, Wolfe ML, Rohatgi A, Lazar MA, Rader DJ. Resistin is an inflammatory marker of atherosclerosis in humans. Circulation. 2005;111(7):932-9.

84. Henao-Mejia J, Elinav E, Jin C, Hao L, Mehal WZ, Strowig T, et al. Inflammasome-mediated dysbiosis regulates progression of NAFLD and obesity. Nature. 2012;482(7384):179-85.

85. Harte AL, Varma MC, Tripathi G, McGee KC, Al-Daghri NM, Al-Attas OS, et al High fat intake leads to acute postprandial exposure to circulating endotoxin in type 2 diabetic subjects. Diabetes Care. 2012;35(2):375-82.

86. Rao R. Endotoxemia and gut barrier dysfunction in alcoholic liver disease. Hepatology. 2009;50(2):638-44.

87. Miyake Y, Yamamoto K. Role of gut microbiota in liver diseases. Hepatol Res. 2013;43(2):139-46.

88. Kim KA, Gu W, Lee IA, Joh EH, Kim DH. High fat diet-induced gut microbiota exacerbates inflammation and obesity in mice via the TLR4 signaling pathway. PLoS One. 2012;7(10):e47713.

89. Wiedermann CJ, Kiechl S, Dunzendorfer S, Schratzberger P, Egger G, Oberhollenzer F, et al. Association of endotoxemia with carotid atherosclerosis and cardiovascular disease: prospective results from the Bruneck Study. J Am Coll Cardiol. 1999;34(7):1975-81.

90. Lehr HA, Sagban TA, Ihling C, Zähringer U, Hungerer KD, Blumrich M, et al. Immunopathogenesis of atherosclerosis: endotoxin accelerates atherosclerosis in rabbits on hypercholesterolemic diet. Circulation. 2001;104(8):914-20.

91. Denecke B, Gräber S, Schäfer C, Heiss A, Wöltje M, Jahnen-Dechent W. Tissue distribution and activity testing suggest a similar but not identical function of fetuin-B and fetuin-A. Biochem J. 2003;376(Pt 1):135-45

92. Srinivas PR, Wagner AS, Reddy LV, Deutsch DD, Leon MA, Goustin AS, et al. Serum alpha 2-HS-glycoprotein is an inhibitor of the human insulin receptor at the tyrosine kinase level. Mol Endocrinol. 1993;7(11):1445-55.

93. Pal D, Dasgupta S, Kundu R, Maitra S, Das G, Mukhopadhyay S, et al. Fetuin-A acts as an endogenous ligand of TLR4 to promote lipid-induced insulin resistance. Nat Med. 2012;18(8):1279-85. 
94. Mori K, Emoto M, Inaba M. Fetuin-A and the cardiovascular system. Adv Clin Chem. 2012;56:175-95.

95. Toma I, McCaffrey TA. Transforming growth factor-beta and atherosclerosis: interwoven atherogenic and atheroprotective aspects. Cell Tissue Res. 2012;347(1):155-75.

96. Simon S, Collop N. Latest advances in sleep medicine: obstructive sleep apnea. Chest. 2012;142(6):1645-51.

97. Tock L, Carneiro G, Togeiro SM, Hachul H, Pereira AZ, Tufik S, et al. Obstructive sleep apnea predisposes to nonalcoholic Fatty liver disease in patients with polycystic ovary syndrome. Endocr Pract. 2014;20(3):244-51.

98. Drager LF, Bortolotto LA, Lorenzi MC, Figueiredo AC, Krieger EM, LorenziFilho G. Early signs of atherosclerosis in obstructive sleep apnea. Am J Respir Crit Care Med. 2005;172(5):613-8.

99. Baguet JP, Hammer L, Lévy P, Pierre H, Launois S, Mallion JM, et al. The severity of oxygen desaturation is predictive of carotid wall thickening and plaque occurrence. Chest. 2005;128(5):3407-12.

100. Minoguchi K, Yokoe T, Tazaki T, Minoguchi H, Tanaka A, Oda N, et al. Increased carotid intima-media thickness and serum inflammatory markers in obstructive sleep apnea. Am J Respir Crit Care Med. 2005;172(5):625-30.

101. Bradley TD, Floras JS. Obstructive sleep apnoea and its cardiovascular consequences. Lancet. 2009;373(9657):82-93.

102. Lui MM, Sau-Man M. OSA and atherosclerosis. J Thorac Dis. 2012;4(2):164-72.

103. Pelsers MM, Hermens WT, Glatz JF. Fatty acid-binding proteins as plasma markers of tissue injury. Clin Chim Acta. 2005;352(1-2):15-35.

104. Ishii J, Wang JH, Naruse $H$, Taga S, Kinoshita M, Kurokawa H, et al. Serum concentrations of myoglobin vs human heart-type cytoplasmic fatty acidbinding protein in early detection of acute myocardial infarction. Clin Chem. 1997:43(8 Pt 1):1372-8.

105. Basar O, Akbal E, Köklü S, Tuna Y, Koçak E, Başar N, et al. Increased H-FABP concentrations in nonalcoholic fatty liver disease. Possible marker for subclinical myocardial damage and subclinical atherosclerosis. Herz. 2013;38(4):417-22.

106. Targher G, Bertolini L, Rodella S, Zoppini G, Lippi G, Day C, et al. Nonalcoholic fatty liver disease is independently associated with an increased prevalence of chronic kidney disease and proliferative/laser-treated retinopathy in type 2 diabetic patients. Diabetologia. 2008;51(3):444-50.

107. Targher G, Bertolini L, Chonchol M, Rodella S, Zoppini G, Lippi G, et al. Nonalcoholic fatty liver disease is independently associated with an increased prevalence of chronic kidney disease and retinopathy in type 1 diabetic patients. Diabetologia. 2010;53(7):1341-8.

108. Hwang ST, Cho YK, Yun JW, Park JH, Kim HJ, Park DI, et al. Impact of nonalcoholic fatty liver disease on microalbuminuria in patients with prediabetes and diabetes. Intern Med J. 2010;40(6):437-42.

109. Mikolasevic I, Racki S, Bubic I, Jelic I, Stimac D, Orlic L. Chronic kidney disease and nonalcoholic Fatty liver disease proven by transient elastography. Kidney Blood Press Res. 2013;37(4-5):305-10.

110. Mikolasevic I, Racki S, Lukenda V, Pavletic-Persic M, Milic S, Orlic L. Nonalcoholic fatty liver disease; a part of the metabolic syndrome in the renal transplant recipient and possible cause of an allograft dysfunction. Med Hypotheses. 2014;82(1):36-9.

111. Băloşeanu CL, Streba CT, Vere CC, Comănescu V, Rogoveanu I. Association between liver histology, carotid ultrasonography and retinal vascular changes in patients with nonalcoholic fatty liver disease (NAFLD). Rom J Morphol Embryol. 2012;53(3):609-14.

112. Saleh DA, Ismail MA, Ibrahim AM. Non alcoholic fatty liver disease, insulin resistance, dyslipidemia and atherogenic ratios in epileptic children and adolescents on long term antiepileptic drug therapy. Pak J Biol Sci. 2012;15(2):68-77.

113. Yang $Y Y$, Huang YT, Lee TY, Chan CC, Yeh YC, Lee KC, et al. Rho-kinasedependent pathway mediates the hepatoprotective effects of sorafenib against ischemia/reperfusion liver injury in rats with nonalcoholic steatohepatitis. Liver Transpl. 2012;18(11):1371-83.

114. Targher G, Bertolini L, Poli F, Rodella S, Scala L, Tessari R, et al. Nonalcoholic fatty liver disease and risk of future cardiovascular events among type 2 diabetic patients. Diabetes. 2005;54(12):3541-6.

115. Mishra S, Yadav D, Gupta M, Mishra H, Sharma P. A study of carotid atherosclerosis in patients with non-alcoholic fatty liver disease. Indian J Clin Biochem. 2013; 28(1):79-83.

116. Li N, Zhang GW, Zhang JR, Jin D, Li Y, Liu T, et al. Non-alcoholic fatty liver disease is associated with progression of arterial stiffness. Nutr Metab Cardiovasc Dis. 2015; 25(2):218-23.
117. Colak Y, Karabay CY, Tuncer I, Kocabay G, Kalayci A, Senates E, et al. Relation of epicardial adipose tissue and carotid intima-media thickness in patients with nonalcoholic fatty liver disease. Eur J Gastroenterol Hepatol. 2012; 24(6):613-8.

118. Sunbul M, Agirbasli M, Durmus E, Kivrak T, Akin H, Aydin Y, et al. Arterial stiffness in patients with non-alcoholic fatty liver disease is related to fibrosis stage and epicardial adipose tissue thickness. Atherosclerosis. 2014; 237(2):490-3.

119. Kozakova M, Palombo C, Eng MP, Dekker J, Flyvbjerg A, Mitrakou A, et al. Fatty liver index, gamma-glutamyltransferase, and early carotid plaques. Hepatology. 2012; 55(5):1406-15.

120. Yilmaz Y, Kurt R, Yonal O, Polat N, Celikel CA, Gurdal A, et al. Coronary flow reserve is impaired in patients with nonalcoholic fatty liver disease: association with liver fibrosis. Atherosclerosis. 2010; 211(1):182-6.

121. Pacifico L, Anania C, Martino F, Cantisani V, Pascone R, Marcantonio A, et al. Functional and morphological vascular changes in pediatric nonalcoholic fatty liver disease. Hepatology. 2010; 52(5):1643-51.

122. Alkhouri N, Carter-Kent C, Elias M, Feldstein AE. Atherogenic dyslipidemia and cardiovascular risk in children with nonalcoholic fatty liver disease. Clin Lipidol. 2011; 6(3):305-314.

123. Villanova N, Moscatiello S, Ramilli S, Bugianesi E, Magalotti D, Vanni E, et al. Endothelial dysfunction and cardiovascular risk profile in nonalcoholic fatty liver disease. Hepatology. 2005; 42(2):473-80.

124. Ampuero J, Gallego-Durán R, Romero-Gómez M. Association of NAFLD with subclinical atherosclerosis and coronary-artery disease: meta-analysis. Rev Esp Enferm Dig. 2015; 107(1):10-6.

125. Guleria A, Duseja A, Kalra N, Das A, Dhiman R, Chawla Y, et al. Patients with non-alcoholic fatty liver disease (NAFLD) have an increased risk of atherosclerosis and cardiovascular disease. Trop Gastroenterol. 2013; 34(2):74-82

126. Torun E, Aydın S, Gökçe S, Özgen IT, Donmez T, Cesur Y. Carotid intimamedia thickness and flow-mediated dilation in obese children with nonalcoholic fatty liver disease. Turk J Gastroenterol. 2014; 25 Suppl 1:92-8.

127. Chen $Y, X u$ M, Wang T, Sun J, Sun W, Xu B, et al. Advanced fibrosis associates with atherosclerosis in subjects with nonalcoholic fatty liver disease. Atherosclerosis. 2015; 241(1):145-50.

128. Ozturk K, Uygun A, Guler AK, Demirci H, Ozdemir C, Cakir M, et al. Nonalcoholic fatty liver disease is an independent risk factor for atherosclerosis in young adult men. Atherosclerosis. 2015; 240(2):380-6.

129. Pastori D, Loffredo L, Perri L, Baratta F, Scardella L, Polimeni L, et al. Relation of nonalcoholic fatty liver disease and Framingham Risk Score to flowmediated dilation in patients with cardiometabolic risk factors. Am J Cardiol. 2015; 115(10):1402-6

130. Puig J, Blasco G, Daunis-I-Estadella J, Loshuertos E, Codina J, Cuba V, et al. Nonalcoholic fatty liver disease and age are strong indicators for atherosclerosis in morbid obesity. Clin Endocrinol (Oxf). 2015; 83(2):180-6.

131. Kim SK, Choi YJ, Huh BW, Park SW, Lee EJ, Cho YW, et al. Nonalcoholic Fatty liver disease is associated with increased carotid intima-media thickness only in type 2 diabetic subjects with insulin resistance. J Clin Endocrinol Metab. 2014; 99(5):1879-84.

\section{Submit your next manuscript to BioMed Central and take full advantage of:}

- Convenient online submission

- Thorough peer review

- No space constraints or color figure charges

- Immediate publication on acceptance

- Inclusion in PubMed, CAS, Scopus and Google Scholar

- Research which is freely available for redistribution 